\title{
Plugando o Desplugado para Ensino de Computação na Escola Durante a Pandemia do Sars-CoV-2
}

\author{
Tainã Ellwanger Tavares \\ Departamento Engenharias, \\ Arquitetura e Computação \\ Universidade de Santa Cruz do \\ $\mathrm{Sul} / \mathrm{UNISC}$ \\ Santa Cruz do Sul, RS, Brasil \\ tainatavares1@mx2.unisc.br
}

\author{
Samanta Ghisleni Marques \\ Departamento Engenharias, \\ Arquitetura e Computação \\ Universidade de Santa Cruz do \\ $\mathrm{Sul} / \mathrm{UNISC}$ \\ Santa Cruz do Sul, RS, Brasil \\ samantaghisleni@gmail.com
}

\author{
Marcia Kniphoff da Cruz \\ Departamento Engenharias, \\ Arquitetura e Computação \\ Universidade de Santa Cruz do \\ $\mathrm{Sul} / \mathrm{UNISC}$ \\ Santa Cruz do Sul, RS, Brasil \\ mcruz@unisc.br
}

\section{RESUMO}

Este trabalho relata a experiência da necessidade encontrada pelo projeto UNISC Inclusão Digital para adequar materiais didáticos de Computação Desplugada em materiais didático-digitaiscomputacionais (Computação Plugada), devido à pandemia causada pelo vírus Sars-CoV-2. O método adotado envolveu consulta à Base Nacional Comum Curricular (BNCC), ao currículo do Centro de Inovação da Educação Brasileira (CIEB) e diretrizes da Sociedade Brasileira de Computação (SBC) para a Educação Básica e produção de animações computacionais. Foram desenvolvidas seis animações e duas delas foram utilizadas com estudantes do $5^{\circ}$ ano para coleta de dados. Os resultados apontam que as animações computacionais representaram um excelente meio de introduzir conceitos de Computação na escola, uma vez que, dos 28 estudantes participantes, $100 \%$ apresentou capacidade de indicar situações em que Algoritmos são empregados para a resolução de desafios, e ainda, $82 \%$ demonstrou ter assimilado o conceito de PC.

\section{PALAVRAS-CHAVE}

Pensamento Computacional, Computação Desplugada, Computação Plugada, Animações Computacionais, Ensino Fundamental.

\section{Introdução}

As competências, as habilidades e objetos de conhecimentos trabalhados na escola já foram denominados conteúdos, mas hoje recebem denominações diferenciadas na BNCC e, independentemente, da nomenclatura, precisam refletir o que a sociedade espera e necessita em relação ao aprendizado das crianças e adolescentes da Educação Básica.

Assim, ao longo dos anos, conforme Manacorda [1], a escola foi se modificando e incluindo novos saberes a serem trabalhados. $\mathrm{O}$ referido autor comenta que a educação era, em meados do século XVIII privilégio de poucos. Hoje, todos os cidadãos possuem direito à educação, conforme Constituição Nacional [2].

Fica permitido aos autores ou a terceiros a reprodução ou distribuição, em parte ou no todo, do material extraído dessa obra, de forma verbatim, adaptada ou remixada, bem como a criação ou produção a partir do conteúdo dessa obra, para fins não comerciais, desde que sejam atribuídos os devidos créditos à criação original, sob os termos da licença CC BY-NC 4.0.

EduComp'21, Abril 27-30, 2021, Jataí, Goiás, Brasil (On-line)

(C)2021 Copyright mantido pelo(s) autor(es). Direitos de publicação licenciados à Sociedade Brasileira de Computação (SBC).
O paralelo traçado entre a escola do século XVIII e a escola de hoje nos encaminha a analisar as habilidades e competências, às quais, os estudantes brasileiros da Educação Básica possuem direito a desenvolver em relação às diferentes áreas citadas na BNCC. Contudo, a Computação é abordada na BNCC de forma incipiente e não há uma orientação efetiva para ser desenvolvida na escola.

Ao contrário do Brasil, em muitos outros países a Computação tem sido trabalhada de forma orientada e sistemática em escolas que já incorporaram a área ao ensino regular como disciplina específica ou integrada às demais áreas do conhecimento [3]. No Brasil, as experiências são variadas, acontecem em projetos especiais, pesquisas ou atividades independentes, sendo que, poucas experiências apresentam o ensino regular de Computação nas escolas.

Pretendemos com este trabalho relatar a experiência de uma atividade desenvolvida no projeto UNISC Inclusão Digital e incentivar que mais professores utilizem nossa produção para introduzir a Computação na escola, além de propor discussão sobre a urgência do Conselho Nacional de Educação (CNE) [4] se mobilizar para desenvolver documento norteador, para efetivo ensino de Computação na Educação Básica. Esse projeto é ofertado há 12 anos e tem a finalidade de contribuir para o desenvolvimento social, na busca da humanização e do desenvolvimento das capacidades cognitivas e lógico-computacionais, para enfrentamento das desigualdades, promoção da humanização e da emancipação do cidadão. $\mathrm{O}$ projeto beneficia crianças, adultos e idosos, sendo que, neste trabalho relatamos uma experiência com crianças. Para atingir esta finalidade o projeto oferta ao público oficinas, palestras, lives e materiais didáticos para o ensino de Computação, desenvolvidos pela equipe que o compõe, sendo que, todas as atividades até então, foram ofertadas de forma presencial.

Com a pandemia causada pelo Sars-CoV-21 foi necessária a produção de materiais digitais-computacionais que pudessem ser utilizados e dessem continuidade à disseminação dos conceitos de Pensamento Computacional (PC).

A atividade envolveu a criação de animações computacionais, inspiradas no material didático de Computação Desplugada do
${ }^{1}$ A COVID-19 é uma doença causada pelo Coronavírus, denominado Sars-CoV-2, que apresenta um espectro clínico variando de infecções assintomáticas a quadros graves. A Organização Mundial da Saúde (OMS) caracterizou as infecções provocadas pelo novo coronavírus (Covid-19) como pandemia, sendo a principal recomendação o isolamento social. Disponível em: https://coronavirus.saude.gov.br/sobre-a-doenca. Acesso em out. de 2020 . 
projeto, disponibilizado na página de internet ${ }^{2}$, que podem ser irrestritamente acessados e utilizados. Foram produzidas 6 animações e duas 2 foram utilizadas com turma de $5^{\circ}$ ano do Ensino Fundamental, em escola que oferta a disciplina regular denominada 'Informática'. Adotamos a realização de aulas remotas em meio à pandemia causada pelo vírus Sars-CoV-2. A disciplina aborda habilidades e competências que envolvem o PC, o Mundo Digital (MD) e Cultura Digital (CD) [5] e inspira suas aulas, e atividades nas diretrizes para o ensino de Computação na Educação Básica da (SBC) e no currículo do Centro de Inovação da Educação Brasileira (CIEB).

O resultado da experiência demonstra que, apesar da pandemia causada pelo Sars-CoV-2, que impediu encontros presenciais e a realização de atividades desplugadas, foi possível abordar os conceitos de PC e Algoritmos, através das animações computacionais, sendo que, $100 \%$ dos estudantes demonstrou ter assimilado e ser capaz de indicar exemplos do emprego de Algoritmos para a solução de problemas reais e ou computacionais, e ainda, $82 \%$ demonstrou ter assimilado o conceito de PC.

Organizamos este relato na seguinte sequência: Referencial Teórico, Trabalhos Relacionados, Metodologia, Resultados e Discussões, Considerações Finais e Referências.

\section{Referencial Teórico}

Buscamos como referencial teórico, bases que nos auxiliassem na compreensão sobre como o ensino de Computação é conduzido no Brasil, através da revisão da BNCC, do currículo do CIEB e das diretrizes da SBC, PC, Computação Desplugada e Plugada, e Animações.

\subsection{Base Nacional Comum Curricular}

A BNCC é o documento governamental que orienta as competências a serem ministrados nas escolas de Educação Básica do Brasil:

"[...] é um documento de caráter normativo que define o conjunto orgânico e progressivo de aprendizagens essenciais que todos os alunos devem desenvolver ao longo das etapas e modalidades da Educação Básica, de modo a que tenham assegurados seus direitos de aprendizagem e desenvolvimento, em conformidade com o que preceitua o Plano Nacional de Educação (PNE)" [6].

A versão final da BNCC foi homologada em novembro de 2019 e conta com texto introdutório ao PC, MD e CD. É afirmado na BNCC: "Temos um documento relevante, pautado em altas expectativas de aprendizagem, que deve ser acompanhado pela sociedade para que, em regime de colaboração, faça o país avançar".

$\mathrm{Na} \mathrm{BNCC}$, a Educação Infantil está estruturada em duas etapas: 1) direitos de aprendizagem e desenvolvimento, e 2) campos de experiências. O Ensino Fundamental está organizado em cinco áreas do conhecimento, sendo: Linguagens, Matemática, Ciências da Natureza, Ciências Humanas e Ensino Religioso; e o Ensino Médio em quatro áreas do conhecimento: Linguagens e suas

\footnotetext{
2 Página de Internet do Projeto UNISC Inclusão Digital (Projeto UID): http://projetouid.weebly.com/

https://drive.google.com/drive/u/3/folders/1135s 7piskdg8ekq3mYtJlol2DgOixqqw
}

Tecnologias, Matemática e suas Tecnologias, Ciências da Natureza e suas Tecnologias e Ciências Humanas e Sociais Aplicadas.

A BNCC traz uma explicação geral e breve sobre PC e os termos 'PC e Algoritmo' são também citados algumas vezes nos textos da Matemática, dos quais destacamos uma passagem:

"Além disso, a BNCC propõe que os estudantes utilizem tecnologias, como calculadoras e planilhas eletrônicas, desde os anos iniciais do Ensino Fundamental. Tal valorização possibilita que, ao chegarem aos anos finais, eles possam ser estimulados a desenvolver o PC, por meio da interpretação e da elaboração de algoritmos, incluindo aqueles que podem ser representados por fluxogramas" [6].

\subsection{As "Diretrizes para ensino de Computação na Educação Básica" da SBC}

A comunidade acadêmica tem proposto documentos norteadores que sugerem habilidades e competências para o ensino da Computação em seus eixos: $\mathrm{PC}, \mathrm{MD}$ e $\mathrm{CD}$ para serem desenvolvidos nas escolas de Educação Básica, do Brasil. A iniciativa desenvolvida pela $\mathrm{SBC}$ em documento próprio é intitulado 'Diretrizes para ensino de Computação na Educação Básica' e salienta: “[...] o documento apresenta uma proposta que, para ser implementada em escolas, deve ser adaptada para o respectivo contexto escolar, estabelece um ponto de partida [...] e pode auxiliar muitas escolas que já ensinam alguns aspectos de Computação" [5]. Apresenta o embasamento teórico sobre a importância do trabalho com Computação na Educação Básica e os objetos de conhecimento, habilidades e competências a serem abordadas nos níveis de ensino, distribuídos por ano escolar.

\subsection{O "Currículo de Referência em Tecnologia e Computação" do CIEB}

O CIEB desenvolveu o "Currículo de Referência em Tecnologia e Computação", contemplando os temas Tecnologia e Computação que tem por objetivo: "[...] oferecer diretrizes e orientações para apoiar redes de ensino e escolas a incluir os temas tecnologia e computação em suas propostas curriculares" [7]. O currículo atende da Educação Infantil ao Ensino Fundamental II e pretende também auxiliar gestores e professores na implementação BNCC. Inicia a sua proposta com PC, MD e Tecnologia Digital.

\subsection{Pensamento Computacional (PC)}

O PC é uma estratégia do pensamento usada para solucionar e resolver problemas de forma criativa e eficaz, utilizando a tecnologia para auxiliar nas tomadas de decisão. Para Wing [8] "O PC descreve a atividade mental que ocorre na formulação de um problema para admitir uma solução computacional. A solução pode ser realizada por um humano ou máquina, ou geralmente, por combinações de seres humanos e máquinas".

O PC envolve selecionar um problema complexo e dividi-lo em uma série de problemas pequenos e mais gerenciáveis (Decomposição). Cada um desses problemas menores pode, então, 
Plugando o Desplugado para Ensino de Computação na Escola Durante a Pandemia do Sars-CoV-2

ser examinado individualmente, considerando como problemas semelhantes foram resolvidos anteriormente (Reconhecimento de Padrões), focando apenas nos detalhes importantes e ignorando informações irrelevantes (Abstração). Como última etapa, passos simples ou regras para resolver cada um dos problemas menores podem ser projetados (Algoritmos) [9]. A Figura 1 um representa os quatro pilares do PC:

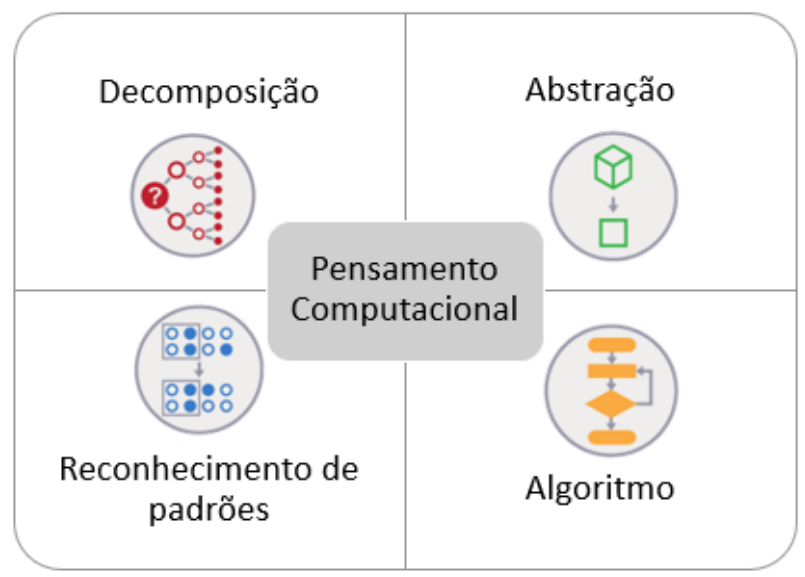

Figura 1: Pilares do PC, adaptado [9]

Através do PC, os alunos recebem desafios e problemas que, para serem resolvidos, irão desafiar o raciocínio computacional, bem como, trabalhar a capacidade de abstrair as informações mais importantes e implementá-las em uma sequência de passos lógicos para atingir um determinado resultado. Além disso, o PC melhora a capacidade de reconhecer padrões, de abstrair informações e, ainda, de trabalhar em grupo.

\subsection{Computação Plugada e Desplugada}

A Computação Plugada utiliza de recursos de hardware e software para desenvolver suas atividades. Geralmente são utilizadas com crianças desafios online como pseudocódigo, sendo exemplos o Scratch e Code.or.

Diferente da Computação Plugada, a Computação Desplugada não necessita de computadores ou acesso à Internet para ser implementada, tornando-a ideal para os mais variados contextos educacionais. A Computação Desplugada é uma estratégia metodológica em que os conhecimentos da Computação são trabalhados sem o uso do computador. Neste formato, os conceitos são apresentados em atividades na forma de jogos e desafios que utilizam papel, lápis, cartas, jogos de tabuleiro, entre outros materiais alternativos concretos. Considerando os eixos da Computação, $\mathrm{PC}, \mathrm{MD}$ e $\mathrm{CD}$, a SBC [5] destaca nas diretrizes que "é muito importante que o PC seja trabalhado (pelo menos inicialmente) de forma desplugada (sem o uso de computadores) nos Anos Iniciais".

Além de facilitar a implementação nas escolas, a Computação Desplugada contribui para o desenvolvimento social, enfrentando as desigualdades, através do desenvolvimento das capacidades cognitivas utilizando uma abordagem acessível a todos, mesmo em ambientes sem à computadores e acesso à Internet.
EduComp'21, Abril 27-30, 2021, Jataí, Goiás, Brasil (On-line)

É importante recordar que as atividades de Computação Desplugada desenvolvidas pelo Projeto UID estão disponíveis para serem utilizadas de forma irrestrita e foram base para a transposição de desafios desplugados para plugados que resultaram nas animações desenvolvidas.

\subsection{Animações}

O termo Animação provém do latim Animus/ anima, que significa ar, respirar, vida, alma e mente. Animar é definido por oportunizar ilusão de vida no que está inanimado [10]. Por definição, animação é o processo no qual cada quadro ou fotograma de um filme é produzido individualmente, quando esses fotogramas são postos em sequência e exibidos em curtíssimos intervalos de tempo, temos a ilusão de movimento contínuo.

A história das imagens animadas inicia com a utilização de brinquedos óticos, objetos nos quais havia alguns desenhos feitos em uma determinada sequência e através do movimento do próprio objeto ocorria uma ilusão de ótica na qual se podia ver o desenho em movimento.

Em 1908 foi projetado o primeiro desenho animado em um projetor de filmes moderno. Ao longo dos anos houve grandes avanços nas tecnologias de criação de animações. Com tantas tecnologias desenvolvidas, surgiram também novas técnicas, como animação 2D, 3D, cartoon, Stop Motion, animação digital, entre outras. Ao se referir ao entretenimento, o foco é a emoção, que é favorecida pelas experiências, também denominadas sensações, que por sua vez são desencadeadas por propriedades que geram estímulos sensoriais e mentais [11].

\section{Trabalhos Relacionados}

Estudamos cinco casos com objetivos similares ao que foi proposto neste trabalho. Os materiais que estudamos apresentam, entre outras questões, como trabalharam PC e Computação, tanto de forma Plugada quanto Desplugada, principalmente no Ensino Fundamental. Um trabalho demonstrou a utilização de animações computacionais para o ensino de conteúdo escolar de energia mecânica. Em nossas buscas não encontramos trabalho relacionado que utilizasse animações computacionais semelhantes à vídeos para atividades de Computação na escola. Os trabalhos que apresentam animações utilizam esse termo para representar situações em que os estudantes usam ferramentas digitais como o Scratch e criam suas animações, o que não é o objeto deste estudo.

Em um dos artigos por nós escolhido, França e Tedesco [12], retratam a realidade do ensino no Brasil, no qual é necessário trabalhar PC, apesar da Computação ainda não ter sido incluída no currículo escolar. Com isso, o trabalho aborda uma série de desafios, enfrentados tanto por professores quanto por alunos, para adaptar o Ensino de Computação à sua realidade.

Outro caso estudado, Castilho et al. [13], relata o resultado de um experimento prático, voltado ao $\mathrm{PC}$, realizado com alunos do Ensino Fundamental. Através de atividades Plugadas, utilizando o software LOGO, similar ao Code.org, e também atividades Desplugadas, como uma atividade em que os alunos programavam uns aos outros, obteve-se como resultado um alto nível de aproveitamento, chegando a $91,7 \%$ em uma turma de $4^{\circ}$ ano.

O artigo de Morales e Gaytán-Lugo [14] aborda a importância de linguagens introdutórias ao ambiente de programação, citando, 
entre outros exemplos, o Scratch, que apesar de ter como foco introduzir os usuários ao PC e ao desenvolvimento de algoritmos, pode ser utilizado para criar histórias e produzir imagens animadas. Já que o desenvolvimento das animações não são o foco central, os alunos acabam não direcionando a atenção necessária para o que produzem, com isso, o artigo reforça a importância de introduzir o desenvolvimento de animações de forma direta aos alunos.

Kuo e Hsu [15] apresentam um estudo no qual utilizam um material denominado Robot City para trabalhar o PC de forma desconectada. O material alvo da pesquisa, é um jogo de tabuleiro que aborda programação e envolve cooperação na resolução das tarefas. Através de atividades práticas os alunos trabalharam com programação estrutural, estruturas sequenciais, condicionais e repetitivas.

$\mathrm{Na}$ pesquisa de Schimiguel et al. [16], foi proposto e avaliado o uso animações interativas para auxiliar no processo de ensino e aprendizagem dos conceitos de energia mecânica. A pesquisa realizada em uma escola pública de Maranhão, foi realizada comparando dois grupos, no qual um grupo utilizou animações computacionais para trabalhar os conceitos abordados através da simulação de elementos comuns do cotidiano, enquanto o outro não. Nos resultados finais foi possível constatar que houve um ganho maior no grupo em que as animações foram utilizadas. $\mathrm{O}$ Quadro 1 demonstra a abordagem dos Trabalhos Relacionados:

\begin{tabular}{|l|c|c|c|}
\hline \multicolumn{1}{|c|}{ Referência } & $\begin{array}{c}\text { Computação } \\
\text { Plugada }\end{array}$ & $\begin{array}{c}\text { Computação } \\
\text { Desplugada }\end{array}$ & Animação \\
\hline França e Tedesco [12] & $\mathrm{X}$ & $\mathrm{X}$ & \\
\hline Castilho et al., [13] & $\mathrm{X}$ & $\mathrm{X}$ & \\
\hline $\begin{array}{l}\text { Morales e Gaytán- } \\
\text { Lugo [14] }\end{array}$ & $\mathrm{X}$ & & \\
\hline Kuo e Hsu [15] & & $\mathrm{X}$ & \\
\hline Schimiguel et al., [16] & & & $\mathrm{X}$ \\
\hline
\end{tabular}

Quadro 1: Comparação das abordagens utilizadas pelos trabalhos relacionados.

França e Tedesco [12] e Castilho et al. [13] abordam tanto a aplicação de atividades plugadas, quanto desplugadas. Morales e Gaytán-Lugo [14] desenvolve estudo utilizando apenas atividades plugadas, enquanto Kuo e Hsu [15] atividades desplugadas. O trabalho encontrado que faz uso de animações, Schimiguel et al. [16], aborda conteúdo escolar que não envolve Computação, mas demonstra que animações são viáveis para a aprendizagem.

\section{A Metodologia}

A metodologia é caracterizada como pesquisa-ação e apresenta dados quantitativos, qualitativos e nossas considerações sobre a experiência. Executamos em duas etapas: a primeira etapa correspondeu à criação de animações inspiradas no material didático de Computação Desplugada, elaborado pela equipe do projeto UNISC Inclusão Digital, no ano de 2019 e ao desenvolvimento do questionário, instrumento de coleta de dados. A segunda etapa correspondeu à utilização das animações com o $5^{\circ}$ ano do Ensino Fundamental de uma escola da rede particular de ensino, que oferta a disciplina de Informática em sua grade curricular. Para a execução da experiência com o $5^{\circ}$ ano utilizamos aula online e duas animações criadas pelo projeto: PC e Algoritmos, e questionário pré-estruturado (APÊNDICE - A) respondido pelos estudantes envolvidos.

\subsection{Público-alvo}

Como público-alvo para utilização das animações escolhemos uma turma de $5^{\circ}$ ano, composta por 28 alunos. Essa escolha se justifica ao considerar o conteúdo e linguagem apresentados nas animações apropriados para a faixa etária em questão. A turma conta com aulas de Informática na grade curricular, com conteúdos que abordam os objetos de conhecimento da Computação e a utilização de ferramentas da Informática, ministradas por professora licenciada em Computação. Estes alunos, em anos anteriores, estudaram conceitos relativos à criptografia, código binário e introdução à programação com linguagem Scratch [17]. Até o momento da experiência com as animações computacionais, os conceitos de PC e Algoritmos não haviam sido apresentados aos estudantes de forma pontuada, mas somente de maneira transversal em outras atividades propostas, ou seja, os estudantes não haviam estudado estes conceitos.

Os períodos de aula têm 50 minutos de duração, porém devido à pandemia causada pelo vírus Sars-CoV-2 as aulas foram realizadas no formato remoto, a partir de 19 de março de 2020 . O período de aula é dividido em duas etapas: aula síncrona via Google $M_{e e} t^{3}$, com duração de 30 minutos e aula assíncrona via plataforma disponibilizada pela escola, em que atividades são disponibilizadas para complementar a carga horária da disciplina, 20 minutos.

\subsection{O plano de ensino da disciplina de Informática do $5^{\circ}$ ano}

O plano de ensino da disciplina de Informática é composto por habilidades e objetos de conhecimento organizados de forma trimestral. Estes objetos de conhecimento estão relacionados às habilidades e competências das "Diretrizes para ensino de Computação na Educação Básica" descritas pela SBC [5] e do "Currículo de Tecnologia e Computação" organizado pelo CIEB [7].

Durante o ano letivo são desenvolvidos conhecimentos sobre a Computação em atividades desplugadas e plugadas (com uso de ferramentas da Informática). No primeiro trimestre letivo, são desenvolvidos conhecimentos relacionados à Arquitetura de computadores e diferenças entre hardware e software. No segundo trimestre, é enfocado o conceito de software e o seu desenvolvimento através de Linguagem de Programação, no caso do $5^{\circ}$ ano, a linguagem escolhida é o Scratch [17]. No terceiro trimestre o estudo sobre a linguagem Scratch e sua lógica de programação é intensificado, porém, neste ano, em virtude da ampliação do uso da Internet como ambiente de aprendizagem, observou-se a necessidade de trabalhar conceitos da Cultura Digital, como o uso das ferramentas online, netiqueta e segurança na rede. Desta forma, foi oportuna a realização da atividade com as animações nesta turma, uma vez que não possuem o contato formal com os conceitos apresentados nos vídeos, porém têm alguns conhecimentos já desenvolvidos na área da Computação. 
Plugando o Desplugado para Ensino de Computação na Escola Durante a Pandemia do Sars-CoV-2

\subsection{Etapa 1 - Desenvolvimento das Animações e do Instrumento de Avaliação}

As animações ${ }^{4}$ criadas no projeto foram desenvolvidas através da ferramenta Powtoon [18]. O Powtoon é uma ferramenta online na qual é possível criar apresentações de slide e vídeos animados no estilo 2D. Apesar de possuir planos pagos, a ferramenta possui uma grande quantidade de recursos gratuitos que podem ser utilizados simplesmente criando uma conta no site.

Com o objetivo de abordar os conceitos presentes no material desplugado desenvolvido pelo projeto de forma lúdica, foram desenvolvidas seis animações sobre: O que é PC, Código Binário, Criptografia, Decomposição e Reconhecimento de Padrões, Algoritmos e Periféricos e Dados.

$\mathrm{Na}$ atividade com o $5^{\circ}$ ano, foram utilizadas duas animações escolhida, dentre as seis: "Pensamento Computacional" (Figura 2) e "Algoritmos" (Figura 3). Essa escolha se justificou devido a turma, ainda, não ter trabalhado com os referidos conceitos, dessa forma, seria possível verificar se as animações auxiliariam na introdução e compreensão dos conceitos.

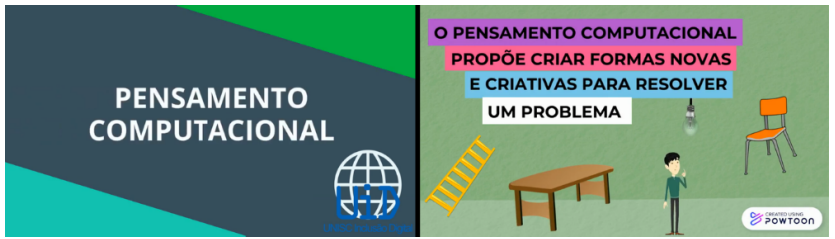

Figura 2: Cena da animação sobre Pensamento Computacional

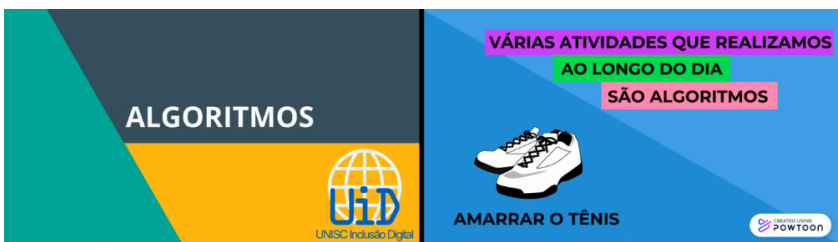

Figura 3: Cena da animação sobre Algoritmos

Além das animações de PC e Algoritmo, a Figura 4 apresenta cenas das outras animações criadas com base no material de Computação Desplugada, mas não utilizadas nas atividades com os estudantes do $5^{\circ}$ ano, como justificado anteriormente.

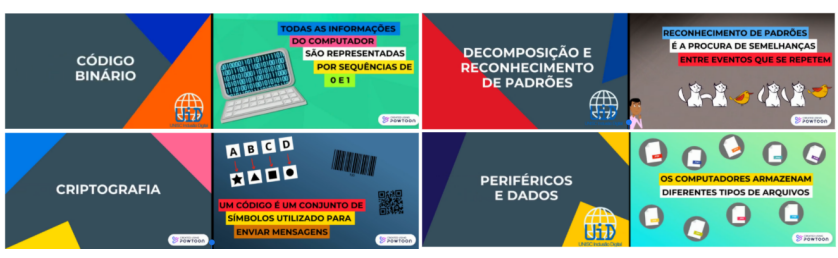

Figura 4: Cenas das demais animações produzidas

As animações têm duração média de dois minutos e apresentam uma linguagem acessível, visto que foram pensadas, principalmente, para crianças e público em geral que não esteja familiarizado com a área da Computação. Além de potencializar os
EduComp'21, Abril 27-30, 2021, Jataí, Goiás, Brasil (On-line)

conceitos através do visual, as animações também foram narradas pela equipe do projeto. As narrações retratam a parte textual, tornando acessível às pessoas com deficiência visual.

\subsubsection{Instrumento de coleta de dados e critérios de avaliação do desempenho dos estudantes}

A fim de verificar a compreensão dos estudantes, durante a aula, após assistirem as animações produzidas, foi desenvolvido um questionário pré-estruturado (Apêndice A) referente aos conceitos do PC e Algoritmo. O questionário foi composto por sete questões que abordaram, além do próprio conceito de $\mathrm{PC}$, definições sobre Decomposição, Reconhecimento de Padrões, Abstração e Algoritmo. Entre as questões haviam cinco de múltipla escolha, uma de resposta múltipla e uma dissertativa.

A demonstração de compreensão dos estudantes foi categorizada em "assimilou" e "não assimilou", considerando os conceitos apresentados nas animações, conforme descritos no Currículo do CIEB [7]:

- $\quad$ PC: Refere-se à capacidade de resolver problemas a partir de conhecimentos e práticas da Computação, englobando sistematizar, representar, analisar e resolver problemas.

- Decomposição: Trabalha o processo que divide os problemas em partes menores para facilitar a resolução.

- Reconhecimento de padrões: Trabalha a identificação de características comuns entre os problemas e suas soluções.

- Abstração: A abstração envolve a filtragem e classificação dos dados, criando mecanismos que permitem separar apenas os elementos essenciais em determinado problema.

- Algoritmo: Trabalha a estratégia ou o conjunto de instruções claras e necessárias, ordenadas para a solução de um problema.

\subsection{Etapa 2 - Desenvolvimento da Experiência}

A aula foi planejada em conjunto entre a equipe do projeto e a professora de Informática da turma do $5^{\circ}$ ano, seguindo metodologia proposta na disciplina. O método das aulas foi proposto pelos autores, com inspiração na metodologia Lego Education [19] e é dividido em quatro momentos: "Start", "Explore", "Challenge" e "Extend", conforme segue:

- "Start" - momento em que a professora provoca e desafia os estudantes a pensar sobre o tema que será abordado;

- "Explore" - neste momento os alunos aprofundam as discussões sobre o tema proposto, através de diferentes materiais.

- "Challenge" - os alunos são desafiados a realizar uma atividade prática e registrar suas aprendizagens.

- "Extend" - ao final, os alunos são convidados a ir além do que foi proposto em aula, através de pesquisa ou desenvolvimento de novas atividades extraclasse.

A realização da atividade compreendeu o período de aula síncrona 30 minutos. Iniciou com um diálogo de apresentação da

4 Página de Internet que disponibiliza as animações: < omitido para revisão> 
proposta de atividade. De forma informal, aos estudantes foi feita seguinte questão: "vocês já ouviram falar em Pensamento Computacional e Algoritmos? Sabem o que significa?" Nenhum dos estudantes afirmou conhecer o termo ou seu significado.

No segundo momento da atividade, os estudantes assistiram às animações: 'Pensamento Computacional' e 'Algoritmos'. Ao final da apresentação das animações os alunos tiveram a oportunidade de debater os conceitos vistos, esclarecer as dúvidas que surgiram e rever as animações.

No terceiro e último momento, os estudantes acessaram o questionário e responderam às questões sobre $\mathrm{PC}$ e Algoritmos, $\mathrm{e}$ seus conceitos. Mesmo após a discussão e esclarecimento de dúvidas, ao acessar o questionário, alguns estudantes solicitaram o link das animações para assistir novamente, enquanto informavam suas respostas. Nenhum estudante solicitou auxílio da professora para interpretar as questões.

No quarto momento, como atividade assíncrona, foi proposto aos estudantes que desenvolvessem pesquisa na Internet sobre os conceitos vistos nas animações. O Quadro 2 demonstra o decorrer da aula:

\begin{tabular}{|l|l|}
\hline Momentos & Atividades \\
\hline Start & $\begin{array}{l}\text { Questionamento inicial, provocação, desafio } \\
\text { sobre PC e Algoritmo }\end{array}$ \\
\hline Explore & Assistir as animações \\
\hline Challenge & Responder o questionário \\
\hline Extend & Pesquisa na internet sobre o tema \\
\hline
\end{tabular}

Quadro 2. Momentos da aula segundo roteiro da disciplina

\section{Resultados e Discussões}

O questionário respondido no terceiro momento da aula revela considerações importantes relacionadas à compreensão dos estudantes sobre os conceitos apresentados nas animações e nos permite inferir o que precisa ser aprimorado nas animações e na condução da aula. O Quadro 3, apresenta um resumo que sintetiza a quantidade de estudantes que consideramos ter assimilado ou não os conceitos de PC e Algoritmos apresentados nas animações:

\begin{tabular}{|c|l|c|c|}
\hline Animações & Conceito/Habilidade & Assimilou & $\begin{array}{c}\text { Não } \\
\text { Assimilou }\end{array}$ \\
\hline \multirow{5}{*}{ PC } & Conceito de PC & $82 \%$ & $18 \%$ \\
\cline { 2 - 4 } & Decomposição & $79 \%$ & $21 \%$ \\
\cline { 2 - 4 } & $\begin{array}{l}\text { Reconhecimento de } \\
\text { Padrões }\end{array}$ & $72 \%$ & $28 \%$ \\
\cline { 2 - 4 } & Abstração & $68 \%$ & $32 \%$ \\
\cline { 2 - 4 } & Algoritmo & $61 \%$ & $39 \%$ \\
\hline \multirow{4}{*}{ Algoritmo } & $\begin{array}{l}\text { Aplicação de um } \\
\text { Algoritmo }\end{array}$ & $100 \%$ & - \\
\cline { 2 - 4 } & $\begin{array}{l}\text { Exemplo de } \\
\text { Algoritmo }\end{array}$ & $75 \%$ & $25 \%$ \\
\hline
\end{tabular}

Quadro 3. Considerações das respostas dadas ao questionário

A partir deste momento apresentamos um aprofundamento da análise às respostas do questionário.

As cinco primeiras questões (APÊNDICE A) solicitaram assinalar uma das quatro possibilidades que respondessem às questões:

I) primeira ( $\left.1^{\text {a }}\right)$ questão: 'Após assistir a animação, o que você entendeu sobre Pensamento Computacional?'. Analisamos que
$82 \%$ dos alunos indicou ser "a resolução de problemas com conceitos da Computação", 4\% ser "a forma como programador pensa" e 14\% ser "uma boa maneira de estudar" e nenhum estudante assinalou "pensar como o computador pensa". Os dados apresentados indicam que grande parte dos estudantes conseguiu estabelecer relação entre os conceitos apresentados no vídeo e o conceito de PC discutido em aula como uma das opções de resposta. Ainda, sobre esta questão, alguns estudantes permanecem relacionando o termo apenas à área da Computação, acreditando que se refere ao pensar do programador, o que indica que o trabalho com PC precisa ter continuidade na turma.

II) segunda ( $\left.2^{\mathrm{a}}\right)$ questão: 'Assinale o que você entende sobre Decomposição'. Analisamos que $79 \%$ dos alunos indicaram que se refere a "conhecer o problema e dividir em partes menores", $10 \%$ "analisar o problema e aumentar partes", 7\% "testar um Algoritmo" e $4 \%$ "apagar partes de um programa". Consideramos que a porcentagem de respostas incorretas que soma $21 \%$, conforme o Quadro 3, é um valor expressivamente grande, pois o termo "decompor" é utilizado desde os anos iniciais do Ensino Fundamental, também em outras áreas do conhecimento como Matemática e Ciências da Natureza, assim, esperávamos uma relação mais próxima dos conceitos relacionados ao $\mathrm{PC}$.

III) terceira ( $3^{\mathrm{a}}$ ) questão: 'Assinale o que você entende sobre Reconhecimento de padrões'. Verificamos que $72 \%$ dos alunos apontam que se refere a "identificar situações que se repetem dentro do problema ou entre problemas", $10 \%$ indicaram que é "reconhecer um erro em um programa" e 18\% marcaram que se refere à "identificar o que há de diferente em um problema" $\mathrm{e}$ nenhum estudante assinalou "reconhecer o final de um problema". A análise das respostas dadas a esta questão aponta que assistir à animação foi suficiente para que a maior parte dos estudantes compreendessem o conceito de Reconhecimento de Padrões, porém as respostas equivocadas mostram que esta habilidade precisa ser retomada em atividades diversificadas, para que os estudantes possam experimentar sua aplicação prática e assimilar o conceito.

IV) quarta $\left(4^{\mathrm{a}}\right)$ questão: 'Assinale o que você entende sobre Abstração'. Identificamos que 68\% dos alunos apontaram que é "escolher o que é o mais importante para resolver um problema", $25 \%$ indicam que "é pensar sobre como deveria ser o problema" e $7 \%$ indicam que se refere à "pensar sobre o que vem antes do problema" e nenhum estudante assinalou "escolher o que é o menos destacado no problema". Os apontamentos feitos pelos estudantes sobre o conceito de Abstração, indicam que, entre os conceitos do PC, este foi um dos mais difíceis de ser assimilado apenas assistindo à animação apresentada. Isso sugere que material específico e complementar sobre o conceito poderia ser desenvolvido pela equipe do projeto, na tentativa de auxiliar os estudantes na sua compreensão.

V) quinta ( $\left.5^{\mathrm{a}}\right)$ questão: "Assinale o que você entende sobre Algoritmo". Verificamos que 61\% dos estudantes indicaram que se refere a "organizar os passos para a solução de um problema e testar", $25 \%$ apontam que se refere a "organizar um passo a passo que não deve ser testado na solução do problema", 10\% marcaram que corresponde a "organizar a escrita do problema" e $4 \%$ acreditam que está relacionado a "listar as ações que o problema não apresentou". Em especial, sobre Algoritmo, uma expressiva quantidade de estudantes $(25 \%)$ apontou como explicação ao conceito "organizar um passo a passo que não deve ser testado na solução do problema". Esta quantidade de respostas equivocadas torna evidente que ou a leitura feita pelos estudantes que assinalaram essa última opção não foi feita com atenção, 
Plugando o Desplugado para Ensino de Computação na Escola Durante a Pandemia do Sars-CoV-2

suprimindo ou negligenciando o "não". Esperávamos que a resposta correta contabilizasse uma quantidade mais expressiva, uma vez que, a turma assistiu à animação específico sobre o conceito, podendo assistir mais de uma vez. E, ainda, em aulas anteriores rotinas foram trabalhadas no Scratch e considerávamos que uma associação fosse possível.

A partir da sexta $\left(6^{\mathrm{a}}\right)$ questão alteramos o caráter das perguntas, sendo a sexta $\left(6^{\mathrm{a}}\right)$ questão de seleção múltipla e a sétima $\left(7^{\mathrm{a}}\right)$ dissertativa:

VI) sexta ( $\left.6^{\text {a }}\right)$ questão: 'O que você considera que para ser feito precisa de um Algoritmo?'. Esta pergunta exigia do estudante a análise de exemplos e a seleção daqueles que contemplavam o uso de Algoritmo na realização de uma tarefa. Os exemplos apresentados contemplavam situações/problemas da vida real ou da Computação, e apesar da dificuldade que 39\% dos participantes demonstrou em conceituar o termo, todos os participantes conseguiram selecionar exemplos de situações em que o emprego de Algoritmos se faz necessário.

VII) sétima ( $\left.7^{\mathrm{a}}\right)$ questão: 'Você saberia descrever um exemplo de Algoritmo? Qual?'. Esta questão solicitava ao estudante a escrita de um exemplo de Algoritmo. Analisamos que, 28\% dos estudantes, apesar dos exemplos apresentados na animação e citados na questão anterior, responderam não saber citar um exemplo para o conceito. O que mostra uma grande dificuldade de alguns estudantes em estabelecer relações entre as questões a eles apresentadas. Por outro lado, entre os $75 \%$ dos alunos que conseguiram citar exemplos de Algoritmos, 48\% descreveu exemplos diferentes dos apresentados na animação e em questões anteriores, demonstrando ótima compreensão do conceito ao estabelecer este tipo de relação.

As respostas marcadas pelos estudantes indicam que, apesar da maioria ter feito boa relação entre os conceitos mostrados nas animações e as opções de respostas apresentadas no questionário, os conceitos do PC, ainda precisam ser trabalhados nas futuras aulas da disciplina, através de ações práticas, atividades desplugadas e materiais complementares.

A experiência relatada nos incentivou a refletir que, as condições ideais de uma escola que oferta disciplina de Informática e possui professora formada na área da Computação deveriam ser estendidas a todas as escolas do Brasil. Quando nos propomos a levantar essa discussão, colocamos em prática a citação da BNCC trazida no item 2.1.1 que convoca a sociedade a acompanhar as ações para avanço do país.

Ao colocar em pauta a discussão sobre $\mathrm{PC}$ na BNCC recordamos do CNE. O CNE é responsável pela BNCC junto ao governo brasileiro e relatos desta natureza são relevantes e contribuem para que o referido conselho possa desenvolver documento complementar à BNCC para orientar o adentramento da Computação na escola, pois é uma urgência social brasileira. $\mathrm{O}$ CNE possui diversos elementos para inspirar essa trajetória, devendo também consultar o currículo do CIEB e diretrizes da SBC.

Consideramos insuficiente a forma como PC e Algoritmos são abordados na BNCC. A passagem trazida no item 2.1.1 que relaciona utilização de calculadoras e planilhas eletrônicas ao desenvolvimento do PC demonstra desconhecimento sobre o que é e como trabalhar PC na escola.

Os Trabalhos Relacionados descritos na seção três apontam casos de sucesso em que a Computação Plugada ou Desplugada foi trabalhada em contexto escolar, obtendo sucesso nos resultados de
EduComp'21, Abril 27-30, 2021, Jataí, Goiás, Brasil (On-line)

aprendizagem. O trabalho Schimiguel et al. [16], também citado na referida seção, deixa evidente que, animações computacionais são ideais para atividades de compreensão de conteúdos escolares.

\subsection{Aprendizados e Limitações}

Diante do relato apresentado, entendemos que o nosso aprendizado aconteceu em muitos sentidos durante e após a experiência. Redigir este relato se tornou uma forma de rever, ainda, com mais profundidade o trabalho desenvolvido.

Revisitar documento normativo como a $\mathrm{BNCC}$ e as diretrizes para o ensino de Computação na escola da SBC [5] e currículo proposto pelo CIEB [7], foram momentos de enriquecimento. Sugerimos aos demais pesquisadores que desenvolvem trabalhos semelhantes ao nosso, revisitem tais documentos para fortalecer conceitos e encontrar direções, bem como, salientar o que deve ser reelaborado, como fizemos no apontamento à BNCC.

A experiência permitiu aprender que é possível desenvolver soluções para dar continuidade ao trabalho que poderia ter sido adiado em meio à pandemia causada pelo Sars-CoV-2. A criação das animações possibilitou à equipe desenvolvedora maior união $\mathrm{e}$ engajamento.

Um ponto positivo a ser destacado é o método das aulas que foi proposto pelos autores, com inspiração na metodologia Lego Education [19]. Este método foi dividido em quatro momentos: "Start", "Explore", "Challenge" e "Extend" e possibilitou a organização da aula e o engajamento dos alunos.

Um limitador do trabalho foi a utilização, somente, de parte das animações com, apenas, uma turma de alunos. Contudo, foi possível observar que uma quantidade significativa de estudantes conseguiu desenvolver os conceitos propostos. Sugerimos que outros professores e pesquisadores utilizem o PowToon para suas atividades, pois é uma ferramenta interessante e que possibilita boas criações.

Temos a convicção de que as animações criadas pelo projeto são um forte incentivo à introdução de conceitos da Computação nas escolas e que muitos professores poderão utilizar em suas aulas, pois estão disponíveis para o uso irrestrito. As animações podem ser utilizadas em aulas de todas as áreas do conhecimento ou em disciplina específica de Computação, Informática, Robótica ou outra nomenclatura que possa ser aferida.

\section{Considerações Finais}

Apresentamos neste relato uma experiência que envolveu a criação de animações computacionais para introdução de conceitos da Computação na escola de Educação Básica e a utilização de duas das seis animações em disciplina regular de Informática. As animações deram continuidade a uma atividade que sempre foi desenvolvida presencialmente. Após as animações serem assistidas e discutidas em aula, os estudantes responderam questionário préelaborado para demonstrar o que puderam assimilar sobre conceitos do PC e Algoritmos.

Os valores dos resultados apresentados no Quadro 3 evidenciam que todos os conceitos foram assimilados pela maioria dos estudantes participantes da pesquisa. A proporção de estudantes que assimilou sempre é superior aos que não assimilaram, sendo que, no item 'Aplicação de um Algoritmo' $100 \%$ dos estudantes demonstrou assimilar o referido conceito. Contudo esses resultados apontam que, são necessárias mais aulas 
para uma assimilação mais efetiva, pois a experiência foi realizada em apenas uma aula.

A experiência tornou evidente que as respostas equivocadas do questionário são de grande importância na construção do material físico (desplugado) e digital (animações), pois nos permitem repensar e aprimorar os materiais desenvolvidos, bem como, retomar os conceitos com os estudantes que demonstraram não ter entendido parte do que lhes foi apresentado.

Sobre o desenvolvimento de materiais didático-digitaiscomputacionais, no caso, as animações, foi muito pertinente a inspiração a partir dos materiais de Computação Desplugada desenvolvidos anteriormente pelo projeto, pois em geral, verificase que a adaptação dos conceitos apresentados nos materiais desplugados em animações são uma boa forma de introdução aos conceitos de PC, mas não são suficientes, é necessário que os conceitos sejam trabalhados também de forma prática e diversificada.

Com a releitura da $\mathrm{BNCC}$, concluímos que é essencial que representantes do CNE participem de eventos de Educação em Computação e busquem estabelecer contato permanente com a $\mathrm{SBC}$, para que conheçam as iniciativas de professores e pesquisadores da área, possibilitando que, o desenvolvimento de ações como as descritas, sejam oportunizados não somente à estudantes de escolas com atividades pontuais, ou aos contextos especiais que participam de projetos, geralmente, encaminhados junto às universidades. Se faz necessária uma redação correta e eficiente na BNCC sobre como competências da Computação devem ser trabalhadas na escola.

Pretendemos dar continuidade ao trabalho com a utilização das demais animações com o $5^{\circ}$ ano e com outras turmas do Ensino Fundamental. Ainda, pretendemos produzir novas animações complementares, observando critérios de usabilidade e experiência do usuário para uma composição estética, e acessível mais elaborada.

\section{AGRADECIMENTO}

Agradecemos à Universidade de Santa Cruz do Sul (UNISC) pelo apoio físico e financeiro ao Projeto UNISC Inclusão Digital (UID) e ao projeto parceiro ' $\mathrm{O}$ uso de estilos cognitivos e de agentes pedagógicos no processo de ensino aprendizagem em ambientes virtuais'.

\section{REFERÊNCIAS}

[1] Manacorda, M. A. História da Educação: da Antiguidade aos nossos dias. 13. ed. São Paulo: Cortez, 2018.

[2] Brasil. Constituição Nacional. Disponível em: http://www.planalto.gov.br/ccivil_03/constituicao/constituicao.htm. Acesso em out. 2020.

[3] Souza, et al., 2019. O desenvolvimento do Pensamento Computacional além do ensino em ciências exatas: uma revisão da literatura. Anais do XXX Simpósio Brasileiro de Informática na Educação (SBIE 2019). Disponível em: $<$ https://www.brie.org/pub/index.php/sbie/article/view/8757/6318>. Acesso em out. 2020.

[4] Brasil. Conselho Nacional de Educação (CNE). Ministério da Educação. Disponível em: Acesso em out. 2020. http://portal.mec.gov.br/conselhonacional-de-educacao/apresentacao. Acesso em out. 2020.

[5] Sociedade Brasileira de Computação (SBC). Diretrizes para ensino de Computação na Educação Básica. Disponível em: $<$ https://www.sbc.org.br/educacao/diretrizes-para-ensino-de-computacaona-educacao-basica>. Acesso em out. 2020
[6] Brasil. Base Nacional Comum Curricular (BNCC). Educação é a Base Brasília, MEC/CONSED/UNDIME, 2017. Disponível em: $<$ http://basenacionalcomum.mec.gov.br/images/BNCC_EI_EF 110518 ve rsaofinal_site.pdf $>$. Acesso em out. 2020.

[7] Centro de Inovação para a Educação Básica (CIEB). Currículo de Tecnologia e Computação. Disponível em: <https://curriculo.cieb.net.br/>. Acesso em out. 2020

[8] Wing, Jeanette M. Computational Thinking: What and Why? 2010. Disponível em:

$<$ http://www.cs.cmu.edu/ CompThink/resources/TheLinkWing.pdf $>$. Acesso em out. 2020.

[9] KS3. Key Stage 3. Bitzise. In BBC Learning. Introduction to computational thinking. Disponível em: https://www.bbc.co.uk/bitesize/guides/zp92mp3/revision/1. Acesso em jan. 2021.

[10] Denslow, Philip Kelly. What is animation and who needs to know? An essay on definitions. In: PILLING, Jayne (Ed.). A reader in animation studies. Sydney: John Libbey, 1997.

[11] Savastano, M. O produto de entretenimento. In: Cobra, Marcos. Marketing do entretenimento. São Paulo: Editora Senac, 2008.

[12] França, R; Tedesco, P. (2015). Desafios e oportunidades ao ensino do pensamento computacional na educação básica no Brasil. Anais dos Workshops do IV Congresso Brasileiro de Informática na Educação (CBIE 2015). DOI: https://doi.org/10.5753/cbie.wcbie.2015.1464.

[13] Castilho, Marcos, et al., (2019). O Pensamento Computacional no Ensino Fundamental I. Anais do XXV de Informática na Escola (WIE 2019). DOI: https://doi.org/10.5753/cbie.wie.2019.461.

[14] Morales, L., Gaytán-Lugo, L. (2016). Computer Animation as a Vehicle for Teaching Computational Thinking. Springer-Verlag Berlin Heidelberg DOI: https://doi.org/10.1007/978-3-319-44447-5 6.

[15] Kuo, W., Hsu, T. Learning Computational Thinking Without a Computer: How Computational Participation Happens in a Computational Thinking Board Game. Asia-Pacific Edu Res 29, 67-83 (2020). DOI: https://doi.org/10.1007/s40299-019-00479-9.

[16] Schimiguel, et al, 2013. A Aplicação de Animações no Ensino de Física. Centro Interdisciplinar de Novas Tecnologias na Educação (CINTED) Universidade Federal do Rio Grande do Sul (UFRGS). DOI: https://doi.org/10.22456/1679- 1916.41675.

[17] Scratch. Linguagem de programação. Disponível em: https://scratch.mit.edu/. Acesso em out. 2020.

[18] Powtoon. Ferramenta para a criação de animação. Disponível em: https://www.powtoon.com/index/. Acesso em mai. 2020.

[19] Lego Education. Disponível em: https://education.lego.com/en-us/. Acesso em jan. 2021.

\section{APÊNDICE A - QUESTIONÁRIO}

1. Após assistir a animação, o que você entendeu sobre

Pensamento Computacional?

- É uma boa maneira de estudar

- É a resolução de problemas com conceitos da Computação

- É pensar como o computador pensa

○ É a forma como programador pensa

2. Assinale o que você entende sobre Decomposição:

- Analisar o problema e aumentar partes

- Testar um Algoritmos

- Apagar partes de um programa

- Conhecer o problema e dividir em partes menores

3. Assinale o que você entende sobre Reconhecimento de Padrões 
○ Identificar situações que se repetem dentro do problema ou entre problemas

○ Reconhecer um erro em um programa

- Identificar o que há de diferente em um problema

$\circ \quad$ Reconhecer o final de um problema

4. Assinale o que você entende sobre Abstração

○ É pensar sobre o que vem antes do problema

- Escolher o que é o mais importante para resolver um problema

- Escolher o que é o menos destacado no problema

- É pensar sobre como deveria ser o problema

5. Assinale o que você entende sobre Algoritmos

- Organizar um passo a passo que não deve ser testado na solução do problema

- Organizar os passos para a solução de um problema e testar

○ Listar as ações que o problema não apresentou

○ Organizar a escrita do problema

6. O que você considera que para ser feito precisa de uma Algoritmo?
$\square \quad$ Fazer um sanduíche
$\square$ Amarrar o sapato
$\square \quad$ Plantar uma árvore
$\square \quad$ Trocar uma lâmpada
$\square \quad$ Escovar os dentes
$\square \quad$ Desenvolver um programa de computador
$\square$ Nenhum dos exemplos se refere a um Algoritmo

7. Você saberia descrever um exemplo de Algoritmo? Qual? 